
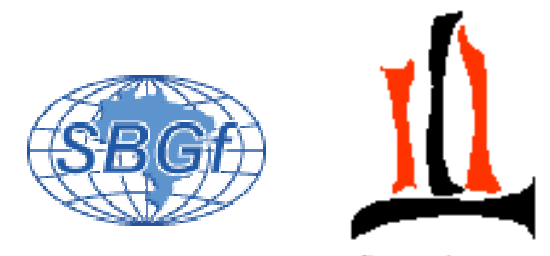

São Paulo 2004

\title{
Sismos induzidos pelo Reservatório de Furnas sentidos em Areado-MG em março de 2003
}

Fernandes, C., Berrocal, J. \& Schramm, D.,

Instituto de Astronomia, Geofísica e Ciências Atmosféricas, Universidade de São Paulo, São Paulo, Brasil

Copyright 2004, SBGf - Sociedade Brasileira de Geofísica

Este texto foi preparado para a apresentação no I Simpósio de Geofísica da Sociedade Brasileira de Geofísica, São Paulo, 26-28 de setembro de 2004. Seu conteúdo foi revisado pela Comissão Tecno-científica do I SR-SBGf mas não necessariamente representa a opinião da SBGf ou de seus associados. E proibida a reprodução total ou parcial deste material para propósitos comerciais sem prévia autorização da SBGt.

\section{Resumo}

A distribuição hipocentral dos sismos de Areado ocorridos em março de 2003, que são de foco muito superficial $(\mathrm{h}<2 \mathrm{~km})$, coincide com a solução de mecanismo focal composto, que embora não corresponda ao pequeno meandro onde estão localizados os epicentros, parece que a orientação da falha corresponde à direção do meandro maior mais próximo, assim como ao rumo de algumas falhas existentes na região

A atividade sísmica de março de 2003, em Areado, coincidiu com um enchimento máximo do reservatório como não ocorria nestes últimos anos desde o início da década de 1990, quando este mesmo fenômeno foi observado no ciclo de 1991 e 1992. Por outro lado o ciclo de março de 2003 durou por alguns meses e depois terminou completamente, caracterizando um ciclo de sismicidade induzida pelo Reservatório de Furnas, com uma zona epicentral semelhante a do ciclo ocorrido em 1991.

\section{Introdução}

Em março de 2003 ocorreu um ciclo de atividade sísmica na cidade de Areado-MG, localizada no sul do Estado de Minas Gerais, na região Sudeste do Brasil. O evento de maior magnitude, deste ciclo, ocorreu no dia 16 de março às $18 \mathrm{~h} 29 \mathrm{~min}$ (hora local, $21 \mathrm{~h} 29 \mathrm{~min}$, UT), e foi sentido com intensidade $5 \mathrm{MM}$ na cidade de Areado.

Esse ciclo foi monitorado parcialmente, pelo Grupo de Sismologia do Instituto de Astronomia, Geofísica e Ciências Atmosféricas da Universidade de São Paulo (IAG/USP). O Observatório Sismológico da Universidade de Brasília também monitorou parte deste ciclo sísmico e efetuou o levantamento de dados macrossísmicos (Marza et al., 2003)

A região onde ocorreram estes eventos, apresenta um nível relativamente baixo de atividade sísmica, típico de regiões intraplaca, caracterizada por um número relativamente pequeno de sismos, raramente excedendo magnitude $\mathrm{m}_{\mathrm{b}}$ 5,0, de acordo com Berrocal et al. (1996 e 2001).

Este trabalho tem como objetivo estudar a atividade sísmica ocorrida em Areado, no intervalo de 22 a 26 de março de 2003, através da localização de hipocentros, da análise da distribuição espacial e do mecanismo focal do sismo principal desse ciclo e dos eventos registrados pelo IAG/USP. Outro objetivo deste trabalho é definir a origem desses fenômenos, se foram ou não induzidos pelo Reservatório de Furnas.

\section{Aspectos geológicos}

A área de estudo está localizada na região limítrofe entre a Faixa Brasília e a Faixa Ribeira. O município de Areado está localizado na borda limite entre o Complexo Varginha-Guaxupé, de idade arqueana e o grupo Araxá do Proterozóico Superior (Fig.1). Esta região aparentemente foi comprimida pelo movimento entre o Craton de São Francisco (porção NE do mapa sismotectônico da Fig. 1) e o Maciço de Paranapanema, que fica sob a Bacia do Paraná (porção SW desse mapa).

Nessa região, como também pode ser visto na Fig. 1, existem várias falhas transcorrentes sinistrais, orientadas principalmente na direção $\mathrm{EW}$ e algumas, como a que ocorre próxima de Areado, orientada na direção SW. Os sismos ocorridos ao redor do Reservatório de Furnas (com magnitudes $m_{b}$ entre 0,7 e 3,1 ), antes do ciclo estudado neste trabalho, são mostrados no mapa sismotectônico da Fig. 1.

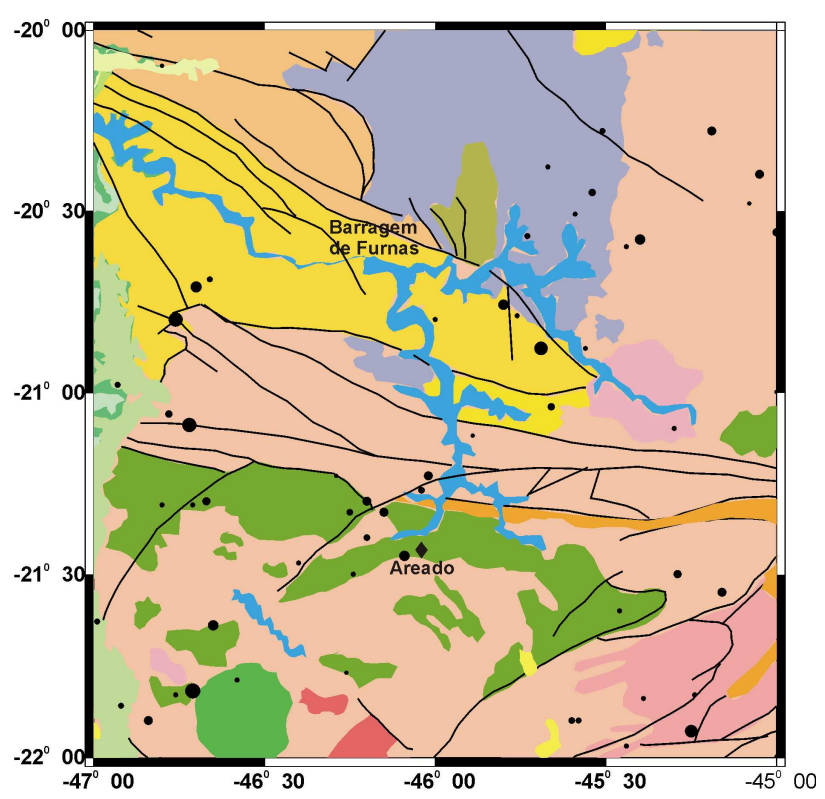

Figura 1 - Mapa sismotectônico da região que abrange o Reservatório de Furnas.

\section{Sismicidade regional}

O nível de atividade sísmica na região Sudeste é relativamente baixo, porém significativo se comparado com outras regiões do Brasil. A região Sul de Minas e sua borda com o estado de São Paulo, que circundam o município de Areado, apresentam um nível significativo de 
atividade sísmica dentro da região Sudeste, onde tem ocorrido o sismo de maior magnitude desta região (sismo de Pinhal-SP de 27.01.1922, $m_{b} 5,1$ ) conforme se apresenta na Fig. 2.

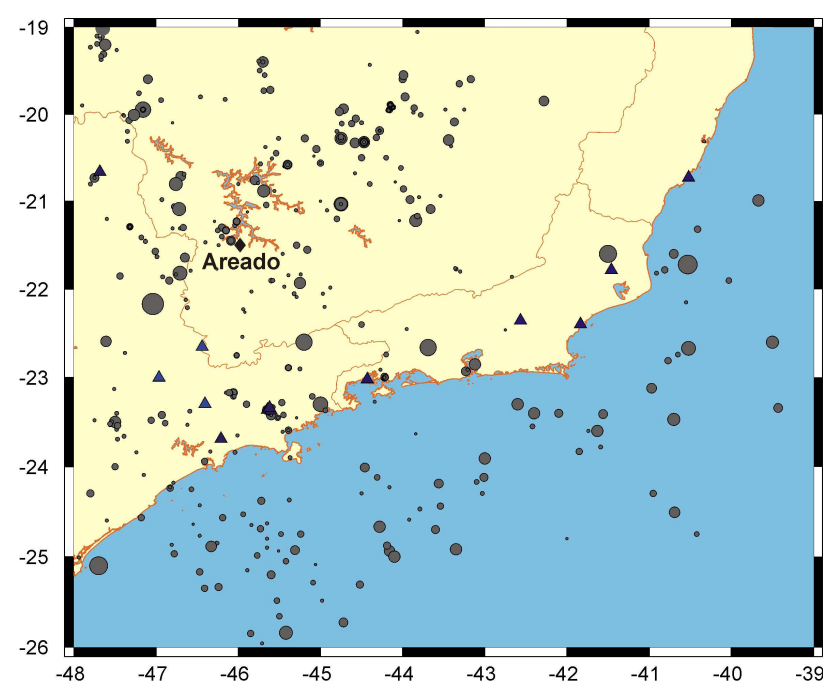

Figura 2 - Mapa de sismicidade da região Sudeste do Brasil com sismos ocorridos entre 1767 e 2002, mostrando o Reservatório de Furnas e a cidade de Areado, assim como algumas estações da rede sismográfica regional (triângulos). O tamanho dos circu-los são proporcionais à magnitude dos sismos entre 1 e $5,1 \mathrm{~m}_{\mathrm{b}}$.

Por outro lado, a área onde está localizado o Reservatório de Furnas, de acordo com Berrocal et al. (1984), não apresenta um nível expressivo de atividade sísmica histórica, comparado com a região circundante, como pode se observado no mapa da Fig. 1. O primeiro sismo conhecido ao redor desse reservatório, ocorreu em São Pedro da União (próximo do Reservatório de Furnas) em 15.11. 1966, um ano e meio depois de ter sido inaugurada a Barragem de Furnas em 12.05.1965, razão pela qual se costuma associar esse sismo com o enchimento do Reservatório de Furnas. Além deste sismo, ocorreu nessa região outro evento um pouco depois, em 1967, em Cabo Verde (35 km ao SE de Areado). Contudo não houve mais atividade nessa região até a década de 1980. Por ser sismos isolados não é possível afirmar que esses eventos tenham sido induzidos pelo Reservatório de Furnas, visto que a atividade induzida por reservatórios hidroelétricos normalmente ocorre em enxames de sismos.

Entretanto, em 11.09.1981 ocorreu um sismo de magnitude $m_{b} 3,1$ nas proximidades de Alfenas, com epicentro muito próximo da porção sul do Reservatório de Furnas. Nos anos seguintes, até 1990, ocorreram outros sete sismos com epicentro nas redondezas de Alfenas, Areado e Alterosa, as três cidades localizadas no extremo sul desse reservatório, com $m_{b}$ variando entre 2,1 e 2,9. Esses eventos, pela sua localização, poderiam corresponder a sismos induzidos por esse reservatório, porém a freqüência de ocorrência dos mesmos, como se menciona antes, não permitem qualificar com certeza essa atividade como sismicidade induzida por reservatórios.
A ocorrência de atividade sísmica na cidade de Areado, na forma de um enxame de eventos é relativamente recente; de acordo com o Boletim Sísmico Brasileiro, começou em janeiro de 1991, quando ocorreram, praticamente $o$ ano inteiro, sismos de pequena magnitude $\left(\mathrm{m}_{\mathrm{b}}\right.$ $\leq 2,7)$ vários deles sentidos com intensidade de até 4 MM. Uma porção deste ciclo, ocorrida em outubro de 1991, foi estudada com detalhe por Blum (1993). Esse ciclo continuou em 1992, mas com uma freqüência menor de ocorrências, porém foram sentidos no mês de junho, dois abalos com intensidade $4 \mathrm{MM}$, um deles teve magnitude $m_{b} 2,9$, que foi o sismo de maior magnitude nesses dois anos. O nível de atividade foi diminuindo nos anos seguintes até 1997 quando foi registrado um único evento nesse ano. A distribuição espaço-temporal desse ciclo, ocorrido entre 1991 e 1997, corresponde a um ciclo típico de sismos induzidos por reservatórios artificiais.

Depois do ciclo sísmico terminado em 1997 só vieram ocorrer novos sismos em Areado em março de 2003

\section{O ciclo sísmico de Areado de março 2003}

\section{O sismo principal deste ciclo}

O evento sísmico que ocorreu em Areado em 16 de Março de 2003 às $21 \mathrm{~h} 9$ min UT, com epicentro em $21,31^{\circ} \mathrm{S} \mathrm{e}$ $46,20^{\circ} \mathrm{W}$ e $\mathrm{m}_{\mathrm{b}} 3,2$ (Boletim Sísmico Brasileiro), é o maior sismo ocorrido nessa localidade e em toda a região próxima ao Reservatório de Furnas, até dezembro de 2003. Este sismo foi sentido com intensidade $5 \mathrm{MM}$, o que causou alguma apreensão na população de Areado e redondezas,. Poucos minutos após este evento, ás 21:35 UT, ocorreu uma réplica com $\mathrm{m}_{\mathrm{b}} 2,7$, também sentida pela população, que teve seu epicentro localizado praticamente no mesmo local que o sismo principal.

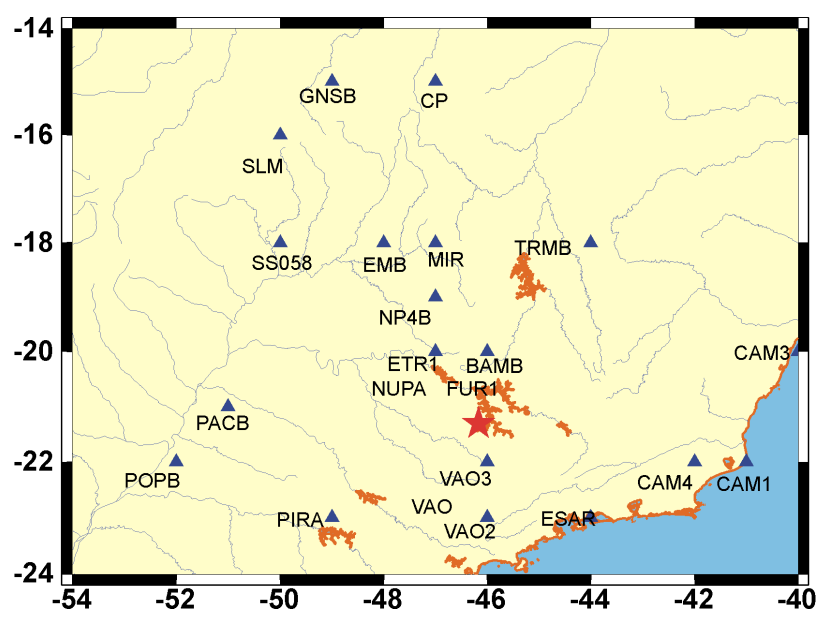

Figura 3 - Estações sismográficas da região sudeste cujos dados foram utilizados para localizar o hipocentro e o mecamismo focal do sismo principal do ciclo de março de 2003.

O sismo principal foi registrado por 22 estações sismográficas da região Sudeste que são mostradas na Fig. 3. $\mathrm{O}$ hipocentro determinado com estes dados foi em $21,3^{\circ}$ $\mathrm{S}$ e $46,2^{\circ} \mathrm{W}$, h $1,1 \mathrm{~km}$ e $\mathrm{H}_{0} 21 \mathrm{~h} 29 \min 41,1 \mathrm{~s}$. A solução do mecanismo focal deste evento utilizando estes dados se apresenta na Fig. 4. O mecanismo focal determinado 
representa uma falha inversa com uma pequena componente transcorrente dextral, conforme os parâmetros mostrados para o plano A nessa figura. Entretanto essa solução não é muito confiável devido ao primeiro impulso da onda $\mathrm{P}$ não ter sido registrado nitidamente nas estações utilizadas, embora seja semelhante ao mecanismo focal composto do ciclo de outubro de 1991 obtido por Blum (1993).

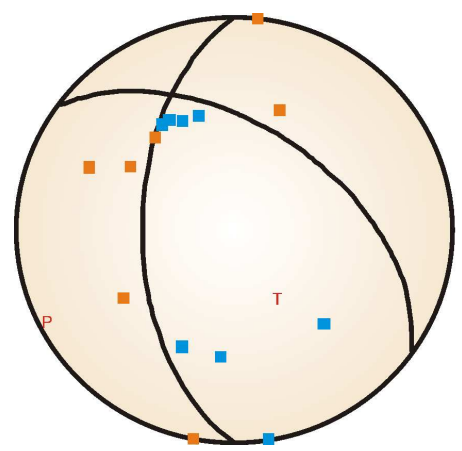

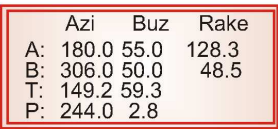

Figura 4 - Mecanismo focal do sismo principal do ciclo de Areado ocorrido em 16 de março de 2003.

\section{Rede sismográfia local}

O Grupo de Sismologia do IAG/USP instalou uma rede telemétrica local em torno de Areado, com três estações de período curto ( $T_{0} 0,5 \mathrm{~s}$ ), sendo uma delas, E1, com três componentes (Z, NS e EW) e as outras duas estações, E2 e E3, (somente com a componente vertical (Fig. 5). O registrador digital utilizado foi o de modelo RRS1, da Kinemetrics, de seis canais, e sismômetros modelo L4C.

Esta rede operou entre os dias 22 e 26 de Março de 2003, e registrou 16 eventos na estação de três componentes e 27 eventos com a rede completa com as três estações.

\section{Determinação de hipocentros}

Foram utilizados 27 eventos com sinais muito claros nas três estações para calcular 0 valor de $\mathrm{V}_{\mathrm{P}} / \mathrm{V}_{\mathrm{S}}=$ 1,735 $\pm 0,022$, utilizando o diagrama de Wadati. Para determinar os hipocentros foi utilizado o programa HYPO71 (Lee \& Lahr, 1975). O modelo utilizado é de uma crosta superior com $V_{P}=6,1 \mathrm{~km} / \mathrm{s}$ de acordo com Perosi \& Berrocal (2003).

Os 27 sismos registrados nas três estações da rede tiveram seus hipocentros localizados com resultados de boa qualidade: valores de RMS menores que 0,03 s e ERH menor que $0,5 \mathrm{~km}$ e ERZ menor que $1,5 \mathrm{~km}$. (Fig. 6)

Os 16 sismos registrados na estação com três componentes tiveram seus epicentros determinados utilizando o azimute de chegada da frente de onda sísmica na estação e a distância epicentral determinada pela diferença de tempo de chegada S-P. Esta distância foi calibrada utilizando as distâncias epicentrais determinadas com o programa HYPO71, resultando numa constante de 8,31 que multiplica pela diferença de tempo S-P. Os epicentros determinados com estes dois conjuntos de eventos são apresentados na Fig. 5.

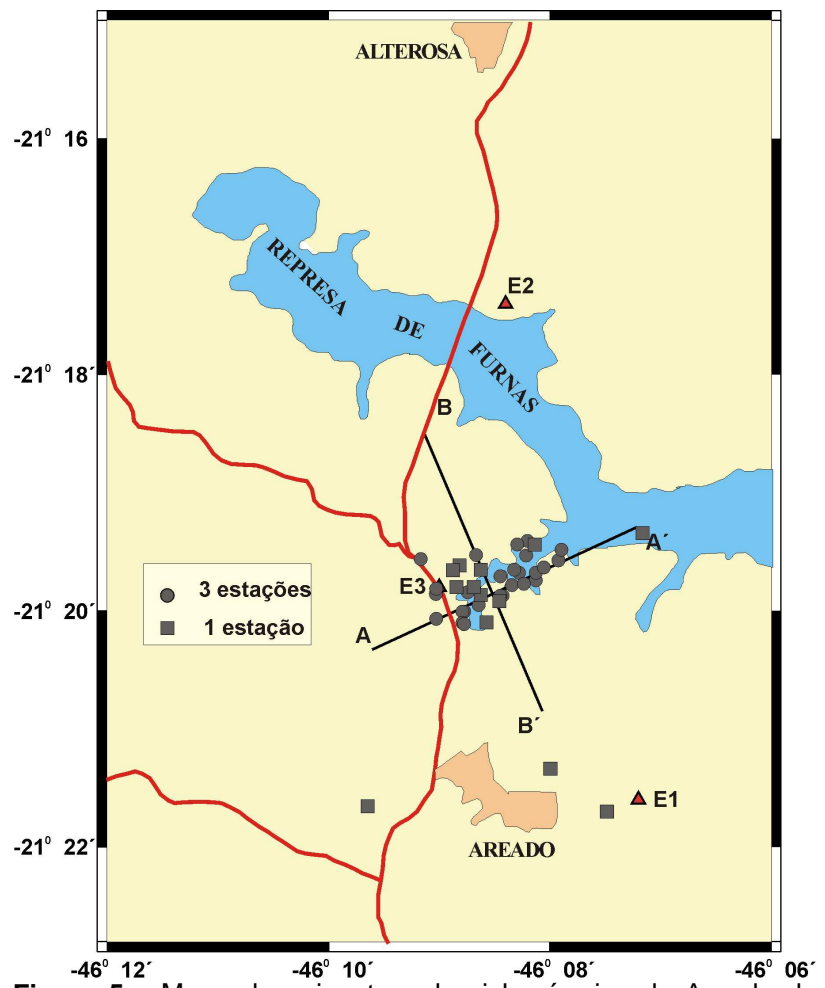

Figura 5 - Mapa de epicentros do ciclo sísmico de Areado de algumas repicas ocorridas em março de 2003.

\section{Distribuição espacial dos hipocentros}

$\mathrm{Na}$ Fig. 5 pode se observar os epicentros, na maioria dos sismos, coincidindo com um dos meandros do reservatório orientado na direção $\mathrm{SW}$, sugerindo um plano de falha nessa direção. Entretanto, a projeção desses hipo-

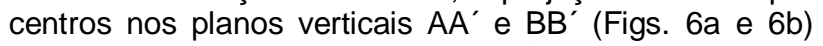
mostram uma distribuição espacial diferente.

A secção $A A^{\prime}$ segue a orientação $S W$ determinada pela distribuição dos epicentros e do suposto plano de falha. No entanto, como se vê na Fig. 6 a os hipocentros mergulham na direção SW e na secção BB' (Fig. 6b) perpendicular ao plano anterior, os hipocentros não mostram nenhum mergulho. Esta distribuição espacial dos hipocentros sugere uma falha mergulhando para SW e com rumo NW-SE.

A

$A^{\prime}$

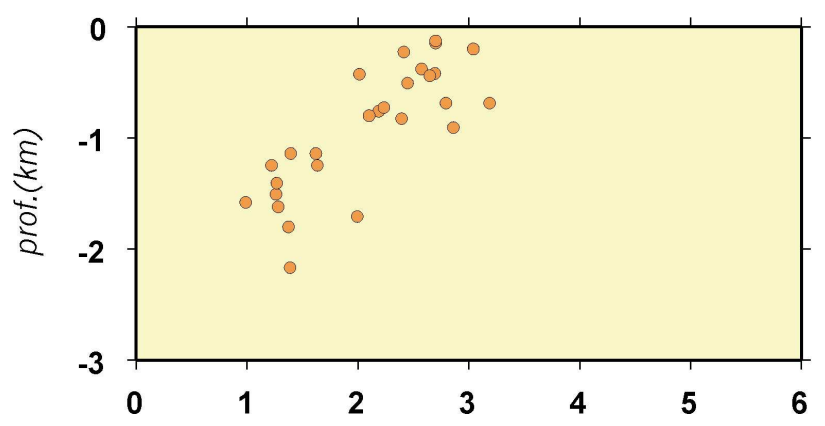

Figura 6a - Secção $A A^{\prime}$ longitudinal ao comprimento da zona epicentral, com os hipocentros registrados nas 3 estações. 


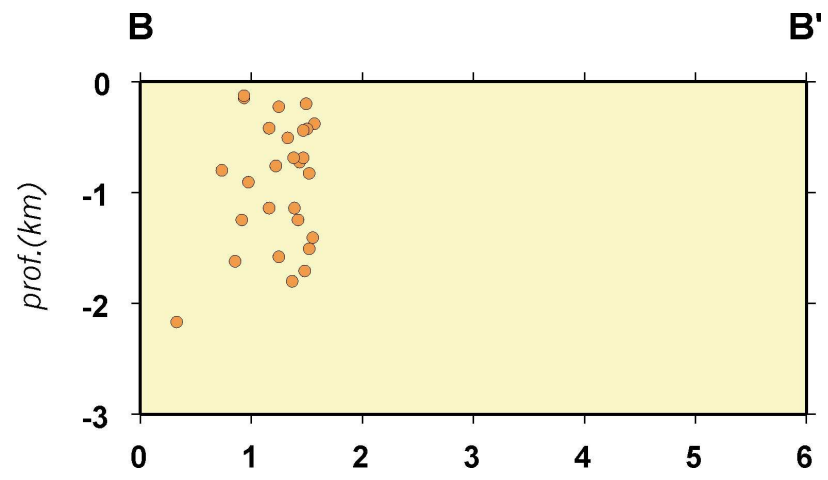

Figura 6 b - Secção $B B^{\prime}$ perpendicular a secção $A A^{\prime}$.

\section{Solução do mecanismo focal das réplicas}

As polaridades do primeiro impulso da onda $P$ registradas nas 3 estações permitiram determinar o mecanismo focal composto para as réplicas do ciclo sísmico de Areado de março de 2003, que é apresentado na Fig. 7. Esta solução indica uma falha reversa com uma componente transcorrente dextral muito pequena, orientada conforme o plano A da Fig. 7.

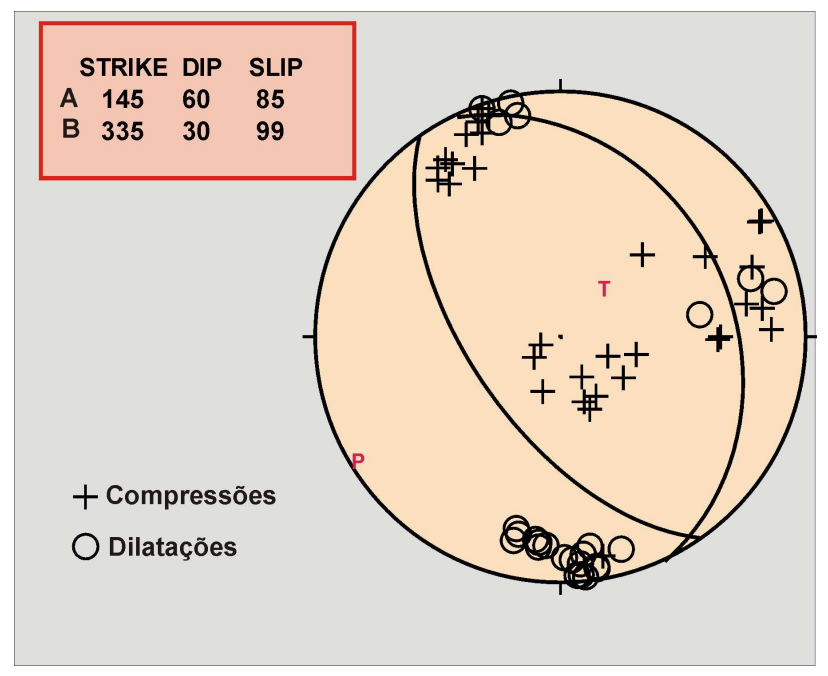

Figura 7 - Solução do mecanismo focal composto das réplicas do ciclo sísmico de Areado de março de 2003.

A solução do mecanismo focal composto das réplicas de Areado concorda com a distribuição espacial dos hipocentros mostrada nas Figs. 6a e 6b. A atividade de 1991 também ocorreu numa falha reversa, orientada aproximadamente NS com mergulho para W (Blum, 1993).

\section{Discussão e conclusão}

A atividade sísmica de março de 2003, em Areado, coincidiu com um enchimento máximo do reservatório como não ocorria nestes últimos anos desde o início da década de 1990, quando este mesmo fenômeno foi observado no ciclo de 1991 e 1992. Por outro lado o ciclo de março de 2003 durou por alguns meses e depois terminou completamente, caracterizando um ciclo de sismicidade induzida pelo Reservatório de Furnas, com uma zona epicentral semelhante a do ciclo ocorrido em 1991 (Blum, 1993).

A distribuição hipocentral desses sismos, que são de foco muito superficial $(\mathrm{h}<2 \mathrm{~km})$, coincide com a solução de mecanismo focal composto, que embora não corresponda ao pequeno meandro onde estão localizados os epicentros, parece que a orientação da falha corresponde à direção do meandro maior mais próximo, assim como ao rumo de algumas falhas existentes na região.

\section{Agradecimentos}

Agradecemos a população de Areado, em especial aos donos do Hotel Areado, pelas informações sobre a sismicidade dessa cidade e pela colaboração prestada ao Grupo de SIsmologia do IAG/USP e aos donos das fazendas que nos permitiram instalar as estações sismográficas. Agradecemos também a Marcelo Assumpção pelas sugestões e discussão deste trabalho. Somos gratos também ao Eng. Luis Galhardo e ao técnico Dennis de Assis Schramm, pela colaboração na preparação e instalação dos equipamentos sismográficos.

\section{Referências}

Berrocal, J., Assumpção, M., Antezana, R., Dias Neto, C.M., Ortega, R., França, H. \& Veloso, J.A.V., 1984. Sismicidade do Brasil. Inst. Astronôm. e Geofís., 320p. São Paulo.

Berrocal, J., Fernandes, C., Bassini, A. \& Barbosa, J., 1996. Earthquake hazard assessment in the Southeastern Brazil. Geofísica Internacional, 35: 257-272.

Berrocal, J., Fernandes, C., Diniz de Almeida, A. \& Roehl, J.L.P., 2001, Avaliação de ameaça sísmica na região SE do Brasil através do método probabilístico. Proc. $7^{\text {th }}$ Int. Cong. Brazilian. Geophys. Soc., p 1264-1267, CD-ROM).

Blum, M., 1993, Cálculo de Magnitudes, Estimativa do parâmetro "b" e considerações sobre a atividade Sísmica de Areado, MG, outubro de 1991, Proc. $3^{0}$ Cong. Bras. Geof. 694-699, em CD-ROM.

Lee, W. H. K. \& Larh, J. C., 1975, HYPO71 (revised): a computer program for determining hypocenter, magnitude, and first motion pattern of local earthquakes, U.S. Geol. Survey, Open-File, 75-311.

Perosi, F. \& Berrocal, J., 2003. Modelo estrutural dos setores Central e Sudeste da Província Tocantins utilizando dados de refração sísmica profunda. $8^{\circ}$ ICBGS, Rio 2003. 